\title{
SHORT-TERM EFFECTS OF T-2 TOXIN \\ OR DEOXYNIVALENOL ON LIPID PEROXIDATION AND THE GLUTATHIONE SYSTEM IN COMMON CARP
}

\author{
Csilla Pelyhe ${ }^{1}$, Benjámin KöVesi ${ }^{1}$, Erika ZÁNDOKI ${ }^{3}$, Balázs Kovács ${ }^{2}$, \\ Judit SZABÓ-FODOR $^{3}$, Miklós MÉZES ${ }^{1 *}$ and Krisztián BALOGH ${ }^{1}$ \\ ${ }^{1}$ Department of Nutrition and ${ }^{2}$ Department of Aquaculture, Szent István University, \\ Páter Károly u. 1, H-2103 Gödöllő, Hungary; ${ }^{3}$ Hungarian Academy of Sciences-Kaposvár \\ University, Mycotoxins in the Food Chain Research Group, Kaposvár, Hungary
}

(Received 28 August 2016; accepted 2 November 2016)

The purpose of this study was to investigate the short-term effects of a single oral dose of T-2 and HT-2 toxin at $0.15,0.33$ and $1.82 \mathrm{mg} \mathrm{kg}^{-1}$ body weight, or deoxynivalenol (DON) and 15-acetyl-DON at $0.13,0.31$ and $1.75 \mathrm{mg} \mathrm{kg}^{-1}$ body weight in common carp. Conjugated dienes and trienes (the early markers of lipid peroxidation) were elevated in all DON-treated groups at the 16th hour, while thiobarbituric acid reactive substances (TBARS; termination marker) were increased at the highest dose of DON at the 16th and 24th hours. T-2 toxin did not cause changes in these parameters. Glutathione content and glutathione peroxidase activity showed higher levels at the 16th hour as the effect of both mycotoxins. The expression of glutathione peroxidase (GPx4) genes (gpx4a and gpx4b) revealed a dual response. Downregulation was observed at the 8th hour, followed by an induction at the 16th hour, at the lowest dose of both mycotoxins. Higher doses revealed long-drawn emergence and an elevation was observed only at the 24th hour. However, at the lowest and highest doses of DON or T-2 toxin the changes in gene expression were delayed, which may be related to the low oxidative stress response, as suggested by the expression profiles of the $\operatorname{nrf} 2$, keapl, gpx $4 a$ and $g p x 4 b$ genes.

Key words: Common carp, deoxynivalenol, glutathione peroxidase, gpx genes, T-2 toxin

Fusarium moulds produce trichothecene mycotoxins, such as deoxynivalenol (DON), a 'type B' trichothecene, which is the most frequent mycotoxin in cereal grains (Binder et al., 2007), and T-2 toxin, a 'type A' trichothecene, which is regarded as the most toxic trichothecene, even in fishes (Anater et al., 2016).

A maximum of $0.25 \mathrm{mg} \mathrm{T}-2$ and HT-2 toxin $\mathrm{kg}^{-1}$ feed is allowed for farm animals according to the EU proposal (2013/165/EU), and for DON the maximum permitted limit is set at $5 \mathrm{mg} \mathrm{kg}^{-1}$ complete feed (2006/576/EC).

*Corresponding author; E-mail: Mezes.Miklos@mkk.szie.hu; Phone: 0036 (28) 410-735; Fax: 0036 (28) 410-804 
The effects of DON and T-2 are not fully described in fishes, and trials with different endpoints showed remarkable differences among fish species. DON and T-2 toxin inhibit the protein, DNA and RNA synthesis in eukaryotic cells (Holladay, 1995) and adversely affect the performance traits and the immune response. Therefore, one of the main features of both trichothecenes is their immunodepressive effect depending on the dose and the duration of exposure, as has been observed in common carp as well (Pietsch et al., 2015). In addition, DON decreases the feed intake depending on its concentration in the diet, as has been reported in rainbow trout (Hooft et al., 2011). T-2 toxin was also found to reduce feed intake in rainbow trout (Poston et al., 1982). Hooft et al. (2011) found DON-induced histopathological changes in the liver and intestine of trout, while Pietsch et al. (2014) in the liver of carp. T-2 toxin was found to reduce the growth rate and increase the mortality of common carp (Balogh et al., 2009).

DON causes oxidative stress in rainbow trout (Šišperová et al., 2015). In a long-term feeding trial with common carp, T-2 toxin resulted in an elevated level of reduced glutathione and affected glutathione peroxidase activity, without increasing the terminal marker of lipid peroxidation, thiobarbituric reactive substances (Balogh et al., 2009). A recent long-term study on common carp with a high dietary inclusion of T-2 and HT-2 toxins or DON and 15-acetyl DON also revealed that the oxidative stress parameters did not differ significantly; however, the expression of phospholipid hydroperoxide glutathione peroxidase genes (gpx4a and gpx4b) showed some, but not conclusive, differences attributable to the effect of T-2 or DON (Pelyhe et al., 2016).

The expression of antioxidant genes including glutathione peroxidase is regulated through the Nrf2/ARE pathway (Suzuki and Yamamoto, 2015). Under unstressed conditions, Nrf2 is constantly ubiquitylated by the Keap1-Cullin3 ubiquitin E3 ligase complex and degraded in proteasomes. In mild oxidative stress Keap1 will be inactivated, therefore the degradation of Nrf2 decreases, and target genes for cytoprotection are activated through the antioxidant response element (ARE) pathway (Taguchi et al., 2011). According to the hierarchical model of oxidative stress (Nel et al., 2006) at low oxygen free radical (ROS) formation, the Nrf2/ARE regulatory mechanism has primary importance, while at a higher rate of ROS formation the NFKB response mechanism is activated and eventually apoptosis will occur.

The purpose of this study was to investigate the short-term effect of T-2 toxin and its major metabolite, HT-2 toxin, or DON and its major metabolite, 15acetyl DON, on some oxidative stress parameters in common carp, in connection with the gene expression of keap1 and $n r f 2$ and also gpx $4 a$ and gpx $4 b$, in order to find out whether oxidative stress is a cause (ROS formation) or a consequence (impairment of antioxidant response) of the effect of trichothecene mycotoxins. 


\section{Materials and methods}

\section{Experimental design}

A total of 160 one-year-old juvenile common carp specimens were obtained from a commercial fish farm (ÖKO 2000 Ltd., Akasztó) and after a oneweek acclimatisation period 154 of them were randomly divided into seven treatment groups (a control group and six experimental groups) in 14 aquaria $(150 \mathrm{~L}$ each). The remaining 6 carp specimens were placed in a separate aquarium (methyl orange treated group) to observe the transit time of feed through the gastrointestinal tract. Each aquarium was used in a semi-static system with dechlorinated, continuously aerated tap water. The light regimen was maintained at a 12:12 h light : dark schedule. Before the start of the experiment one carp was taken out from each experimental group and six of them served as absolute control (0 hour); thus, at start of the experiment 21 animals/experimental group were treated with the control and the experimentally contaminated feed injected by gavage directly into the stomach once. The six fish in the methyl orange treated group received dyed $(1 \% \mathrm{w} / \mathrm{w})$ control feed in the same way.

At the start of the experiment the body weight of the fish was $35.92 \pm 2.82 \mathrm{~g}$. Water temperature was $19 \pm 1{ }^{\circ} \mathrm{C}$.

An appropriate amount of mycotoxin-containing fungal culture was mixed with ground and extruded growth feed for carp (GARANT Aqua Classic ${ }^{\mathrm{TM}}$, Garant-Tiernahrung, Pöchlarn, Austria) and diluted to $5 \mathrm{ml}$ of water immediately before use. The nutrient content of the diet (on a dry matter basis) was $30 \%$ crude protein, $7 \%$ crude fat, $5 \%$ crude fibre, $7.5 \%$ crude ash and $50.5 \%$ nitrogenfree extract. The measured mycotoxin concentrations of the control diet $(1 \mathrm{~kg})$ were as follow: T-2 $<0.02 \mathrm{mg}$, HT- $2<0.02 \mathrm{mg}$, DON $<0.02 \mathrm{mg}$, and 15-acetyl DON: $<0.02 \mathrm{mg}$. Six experimental diets were experimentally contaminated, containing $(1 \mathrm{~kg}) \mathrm{T} 1: 5.82 \mathrm{mg} \mathrm{T}-2$ and $4.97 \mathrm{mg}$ HT-2; T2: $12.72 \mathrm{mg} \mathrm{T}-2$ and $10.95 \mathrm{mg}$ HT-2; T3: $70.72 \mathrm{mg}$ T-2 and $60.31 \mathrm{mg} \mathrm{HT}-2$; D1: $8.56 \mathrm{mg}$ DON and $0.47 \mathrm{mg} 15$-acetyl DON; D2: $21.02 \mathrm{mg}$ DON and $1.13 \mathrm{mg} 15$-acetyl DON; and D3: $120.74 \mathrm{mg}$ DON and $5.18 \mathrm{mg} 15$-acetyl DON. The mycotoxin exposure of the experimental groups was calculated according to the individual body weight and given the amount of experimentally contaminated feed which contained the intended mycotoxin content of the particular group (Table 1).

\section{Table 1}

Mycotoxin exposure ( $\mathrm{mg} \mathrm{kg}^{-1}$ body weight) of the experimental groups

\begin{tabular}{lcccccc}
\hline Experimental groups & T1 & T2 & T3 & D1 & D2 & D3 \\
\hline $\begin{array}{l}\text { T-2 and HT-2 toxin } \\
\text { DON and 15-acetyl DON }\end{array}$ & 0.15 & 0.33 & 1.82 & & & \\
\hline
\end{tabular}


Production of mycotoxins and analyses

DON was produced by Fusarium graminearum (NRRL 5883) and T-2 toxin by Fusarium sporotrichioides (NRRL 3299) strains on corn substrate according to Fodor et al. (2006).

DON and 15-acetyl DON content of the feed was determined according to Pussemier et al. (2006), while T-2 and HT-2 concentration was measured by HPLC after immunoaffinity cleanup (Trebstein et al., 2008).

\section{Sampling and biochemical determinations}

Fish were over-anaesthetised with clove oil and decapitated before sample collection. Liver samples were taken from 6 carp specimens before the start of the trial (absolute control: 0 hour) and from 6 carp in each group at every 8th hour during a 24-h period. All samples were frozen in liquid nitrogen and stored at $-80{ }^{\circ} \mathrm{C}$ until analysis.

To investigate lipid peroxidation, the amounts of conjugated dienes (CD) and trienes (CT) were measured as markers of the initiation phase, according to the AOAC (1984) method and by measuring the absorption at $232 \mathrm{~nm}$ and $268 \mathrm{~nm}$, respectively. The concentration of thiobarbituric acid reactive substances (TBARS) as termination phase marker was determined by colour complex formation with 2-thiobarbituric acid (Botsoglou et al., 1994) and expressed as malondialdehyde, using 1,1,3,3 tetraethoxypropane as standard (Fluka, Buchs). Reduced glutathione (GSH) concentration was measured as described by Rahman et al. (2007) and the activity of glutathione-peroxidase (GPx) according to Lawrence and Burk (1976). The activity of glutathione S-transferase (GST) was measured by the use of a commercial kit (Sigma, St. Louis) according to the method of Habig et al. (1974), and glutathione reductase (GR) activity with a commercial kit (Sigma, St. Louis) according to the method of Smith et al. (1988).

Determination of TBARS was carried out in a native 1:9 homogenate of liver in isotonic saline $(0.65 \% \mathrm{w} / \mathrm{v} \mathrm{NaCl})$, while the other parameters in the $10,000 \mathrm{~g}$ supernatant fraction of the homogenates.

GSH content and the activities of GPx, GST and GR were calculated to the protein content of the $10,000 \mathrm{~g}$ supernatant fraction of liver homogenate, which was measured using Folin-phenol reagent (Lowry et al., 1951).

\section{$R N A$ isolation, reverse transcription and $q P C R$}

Total RNA was purified with Trizol reagent (Molecular Research Centre, Cincinnati) in Phase Lock Gel tubes (5Prime GmbH, Hamburg) from $6 \mathrm{mg}$ liver homogenates, according to the manufacturer's instructions. RNA was DNase treated according to the protocol of the supplier (QUIAGEN, Germantown) to avoid any genomic DNA contamination. The quality and integrity of total RNA were verified by agarose gel electrophoresis and by NanoPhotometer (Implen 
$\mathrm{GmbH}$, Munich) measurement. All samples were accepted with the ratios of absorption 260:280 nm higher than 2.0. A standard protocol was used for cDNA production with RevertAID reverse transcriptase and random nanomer primer from $1 \mu \mathrm{g}$ of total RNA. The primers used for the quantification of the mRNA transcriptional levels of the target and endogenous control gene ( $\beta$-actin) were chosen based on the literature (Hermesz and Ferencz, 2009; Jiang et al., 2015) and are shown in Table 2.

Table 2

Primers of target (gpx4a and gpx4b) and endogenous control ( $\beta$-actin) genes

\begin{tabular}{lll}
\hline Gene & \multicolumn{1}{c}{ Forward $\left(5^{\prime}-3^{\prime}\right)$} & \multicolumn{1}{c}{ Reverse $\left(5^{\prime}-3^{\prime}\right)$} \\
\hline$\beta$-actin & GCAAGAGAGGTATCCTGACC & CCCTCGTAGATGGGCACAGT \\
gpx4a & GGAACCAGGAACAAATTCCC & AGATCCTTCTCCACCACGCTTG \\
gpx4b & CTACAAGGCAGAGTTTGACCTC & CTTGGATCGTCCATTGGTCC \\
nrf2 & TTCCCGCTGGTTTACCTTAC & CGTTTCTTCTGCTTGTCTTT \\
keap1 & GCTCTTCGGAAACCCCT & GCCCCAAGCCCACTACA \\
\hline
\end{tabular}

Real-time PCR was carried out in pooled samples from equal amounts of cDNA per 6 individual carp specimens for each sampling point per treatment with five technical replicates which was found to be a valid method for gene expression analyses (Kendziorski et al., 2003). The PCR reaction was performed in low-profile, clear PCR tubes and caps with Step One Plus ${ }^{\mathrm{TM}}$ Real Time PCR systems (Thermo Fisher Scientific, San Jose). For the qPCR, Maxima SYBR Green qPCR Master Mix ( $1 \times$ final concentration) reaction mixture (Thermo Fisher Scientific, San Jose), $2.31 \mathrm{pM} / \mu$ l primers, $2.5 \mathrm{mM} \mathrm{MgCl}_{2}$ and $5 \mathrm{ng} \mathrm{cDNA}$ were used in $12.5 \mu \mathrm{L}$ final volume per reaction. In addition, no-template controls were also performed for each primer pair. The PCR profile for the gpx4a and gpx4b target genes consisted of $95^{\circ} \mathrm{C}$ for 10 min for pre-amplification denaturation (PAD), and $95^{\circ} \mathrm{C} 15 \mathrm{sec}, 55^{\circ} \mathrm{C} 30 \mathrm{sec}$ and $70{ }^{\circ} \mathrm{C} 30 \mathrm{sec}$ for 45 cycles, for $n r f 2$ and keapl target genes $95^{\circ} \mathrm{C}$ for $10 \mathrm{~min} \mathrm{PAD}$, and $95^{\circ} \mathrm{C} 15 \mathrm{sec}, 60^{\circ} \mathrm{C} 30 \mathrm{sec}$ and $70{ }^{\circ} \mathrm{C} 30 \mathrm{sec}$ for 45 cycles, where SYBR Green signal was detected at the end of the extension period. The amplified products were verified by melting curve analysis and gel electrophoresis. The threshold cycle $(\mathrm{Ct})$ of the target genes (gpx4a, gpx4b, nrf2 and keapl) and the endogenous housekeeping control gene $(\beta$-actin), which has no known interaction with oxidative stress or mycotoxins, was determined by StepOne ${ }^{\mathrm{TM}} / \mathrm{StepOnePlus}{ }^{\mathrm{TM}}$ Software v2.2 (Thermo Fisher Scientific, San Jose) and the delta $\mathrm{Ct}$ values $(\Delta \mathrm{Ct})$ and relative quantification $\left(\mathrm{RQ}=2^{\wedge}-\Delta \Delta \mathrm{Ct}\right)$ values were calculated by the formula described by Livak and Schmittgen (2001) 


\section{Statistical methods}

Statistical analysis of data (two-way analysis of variance, one-way analysis of variance by Student-Newman-Keuls post-hoc test, calculation of means and standard deviations) was performed by MedCalc for Windows, version 12.3 (MedCalc Software, Ostend, Belgium).

\section{Ethical issues}

The experimental protocol was authorised by the Food Chain Safety and Animal Health Directorate of the Pest County Agricultural Office, under permission number XIV-1-001/1880-5/2011.

\section{Results}

The approximate transit time of the methyl-orange-dyed control feed in the control group was $16 \mathrm{~h}$, which was monitored by the first appearance of the coloured faeces after feed intake.

In the 24-h period, between the 8th and 16th hour of mycotoxin exposure mortality $(19 \%)$ was observed only in the T3 group, which was treated with the highest T-2 toxin dose.

Parameters of the initial phase of lipid peroxidation (CD and CT levels) were elevated in all DON-treated groups at the 16th $\mathrm{h}$ (Table 3 ). In the groups treated with T-2 toxin this parameter was less affected, only a slight elevation was observed at the 16th $\mathrm{h}$. However, in the group treated with the highest dose of T-2 toxin (T3) CD level was significantly higher at the 8th $h$ than in the control group (Table 3 ).

The meta-stable end product of lipid peroxidation (TBARS) showed an elevation only as an effect of the highest applied dose of DON (D3) at the 16th and 24th $\mathrm{h}$ of mycotoxin exposure, while in the groups treated with a lower DON dose only a slight elevation was found (Table 4).

The parameters of antioxidant defence showed a rapid and marked response to ROS formation in all of the mycotoxin challenged groups. GSH content was significantly higher in all experimental groups as compared to the control in all groups treated with T-2 toxin and also at the highest dose of DON (D3) at the 16th $\mathrm{h}$ (Table 5). GPx activity also showed elevated levels at the 16th hour, and the difference was significant as compared to the control in the T1, D1, T3 and $\mathrm{D} 3$ groups, and also at the 8th $\mathrm{h}$ in the $\mathrm{T} 3$ group. However, these parameters returned to the control level at the 24th $\mathrm{h}$ of mycotoxin exposure (Table 5). GST activity was significantly lower at the 8 th $\mathrm{h}$ in the T3 group, while it showed a significant elevation in the T1 and D2 groups at the 16th and 24th h (Table 6). 


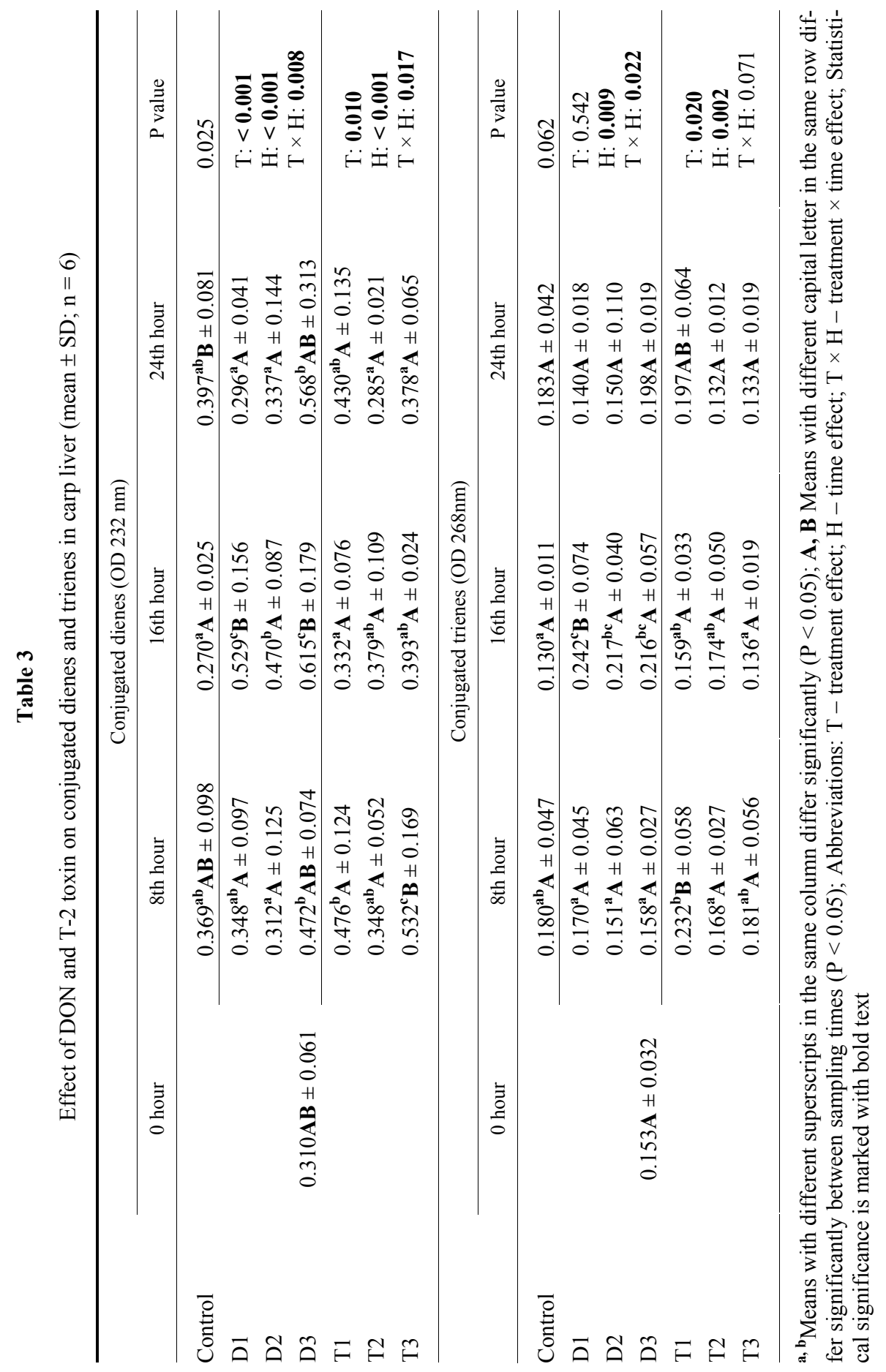




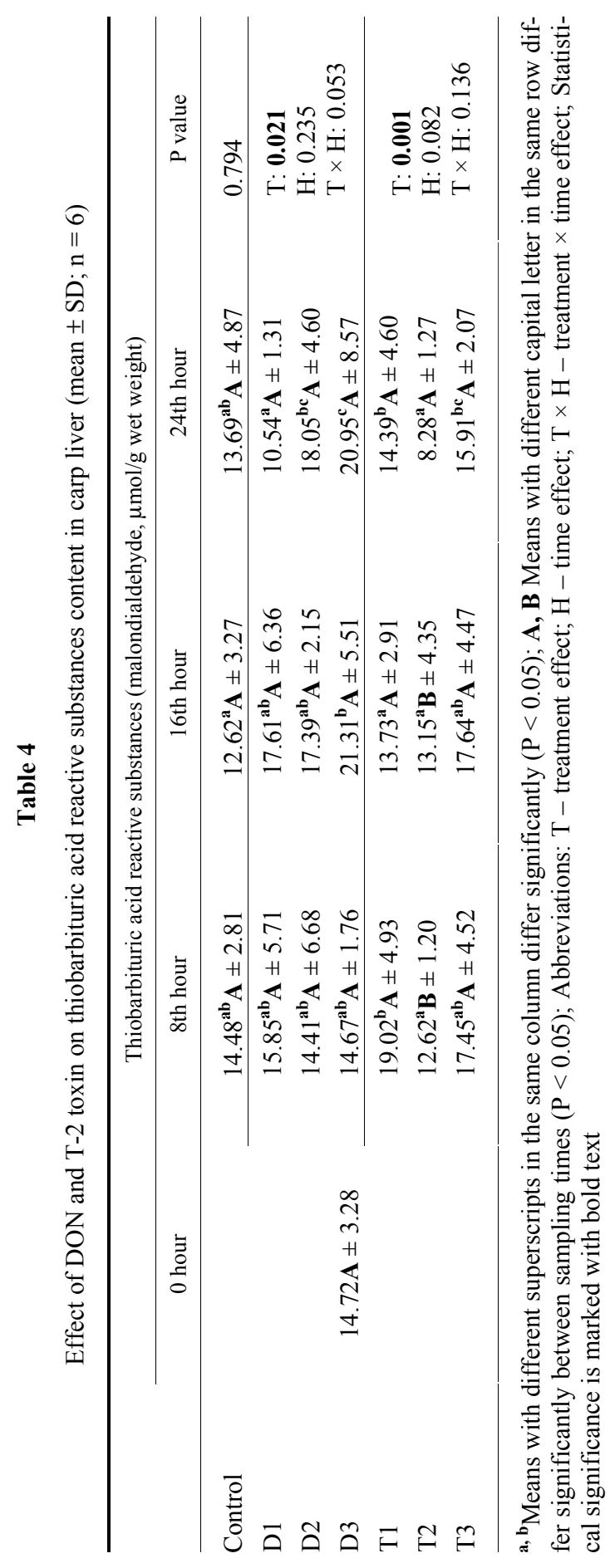




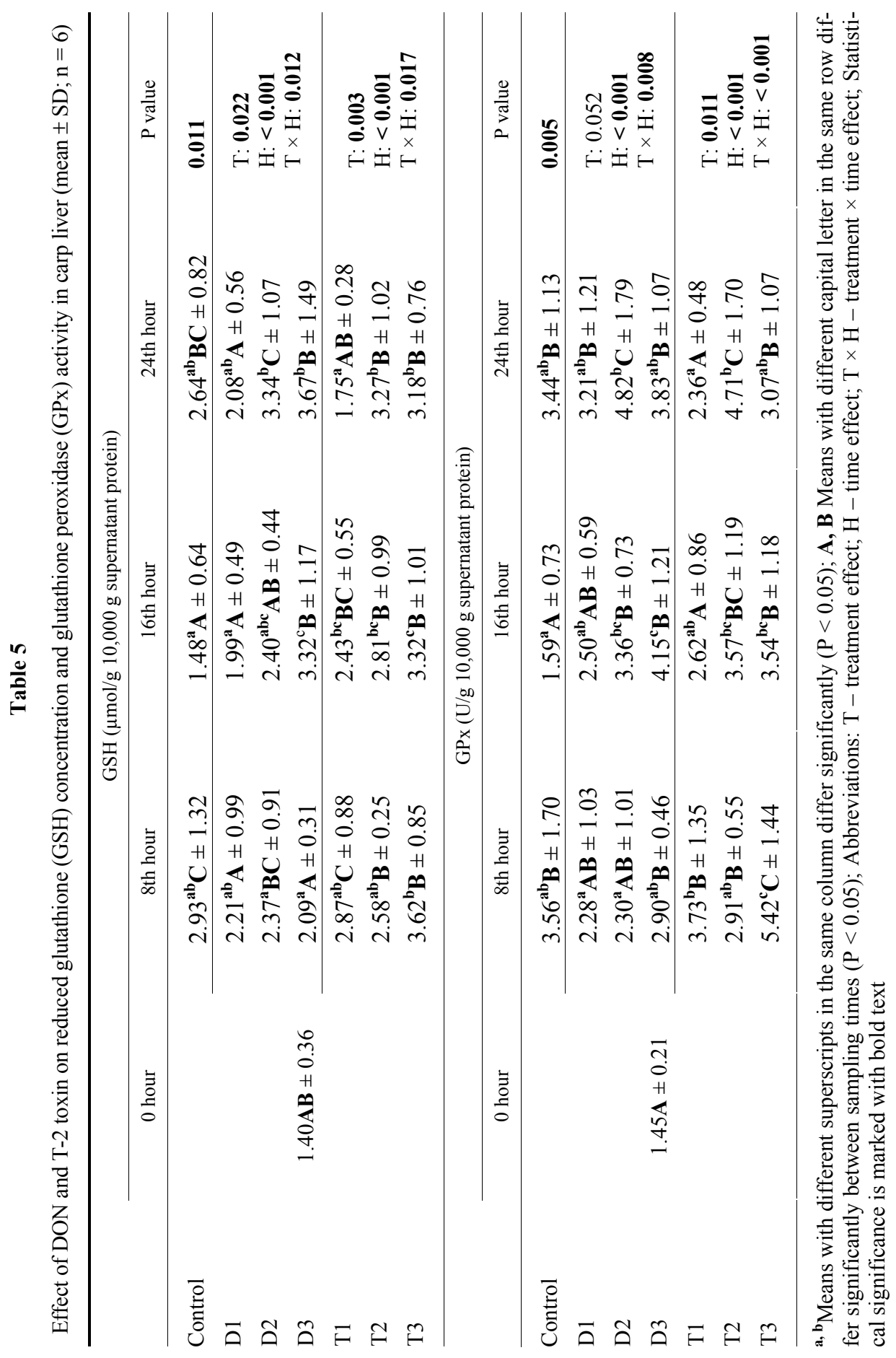




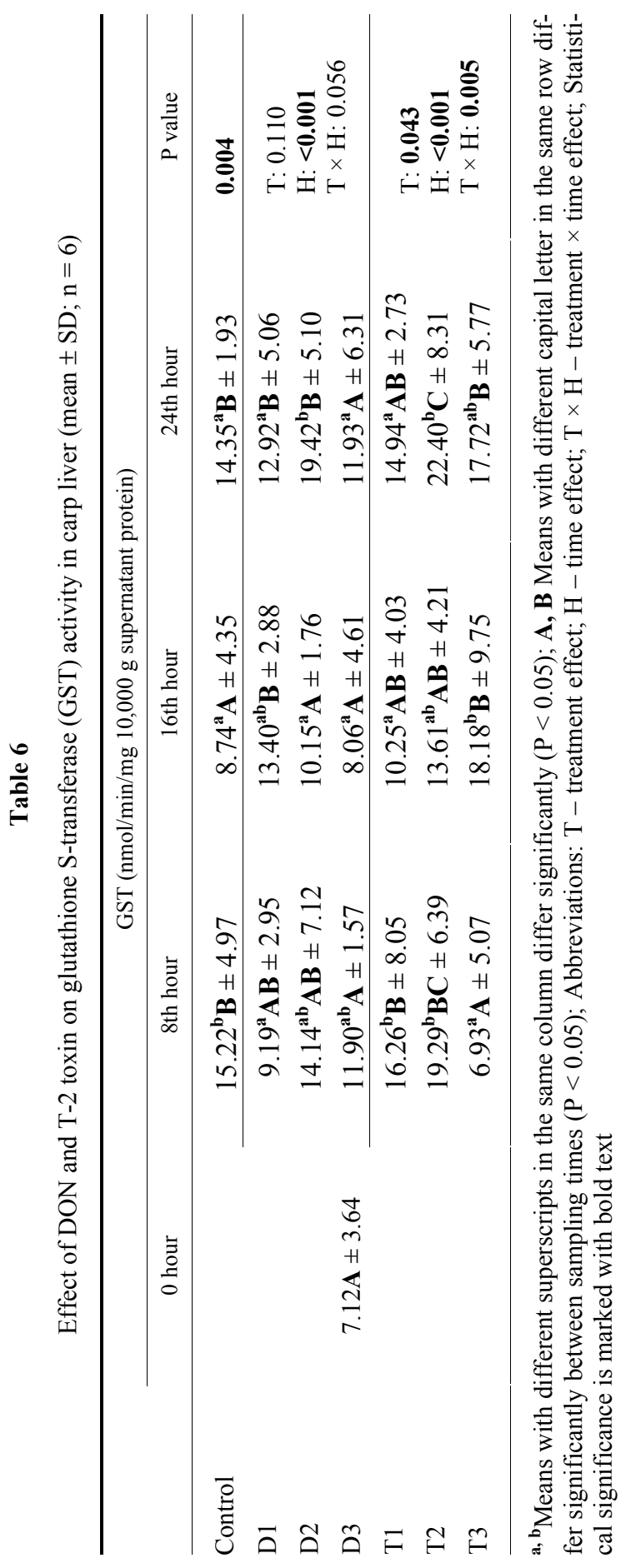




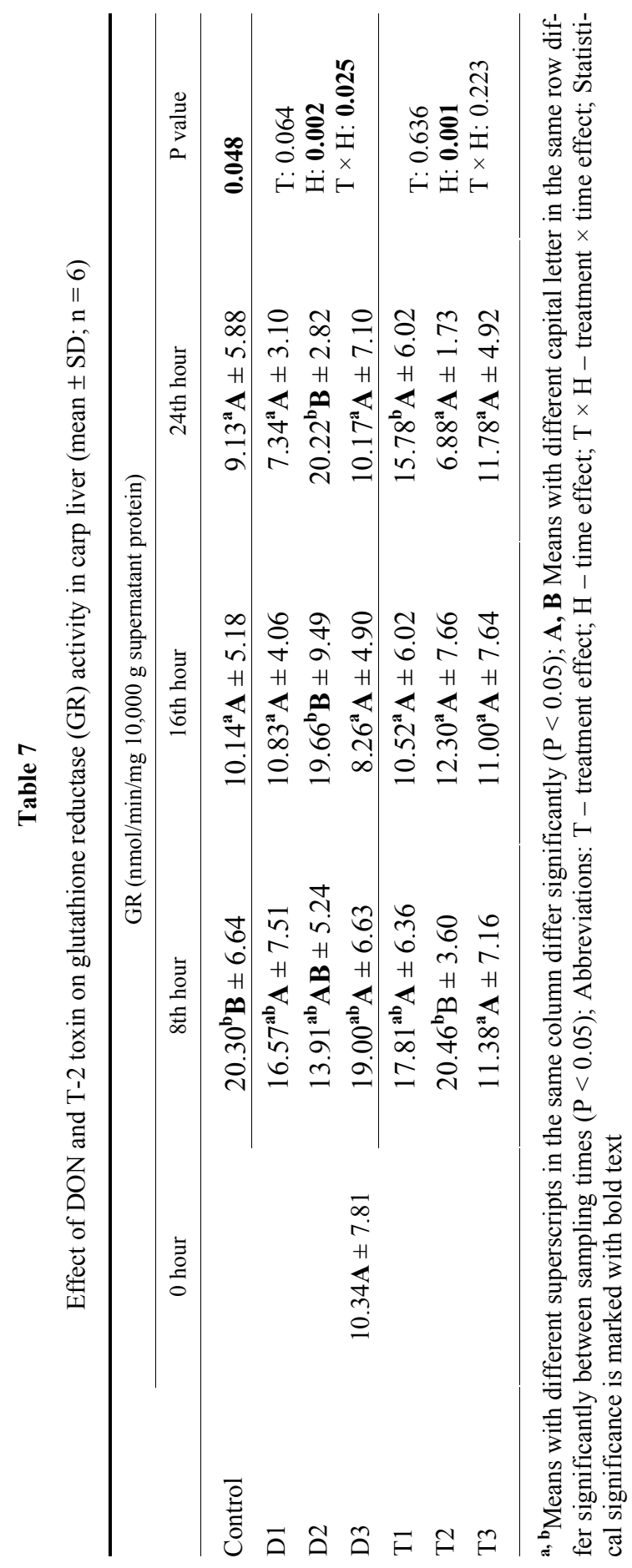


PELYHE et al.

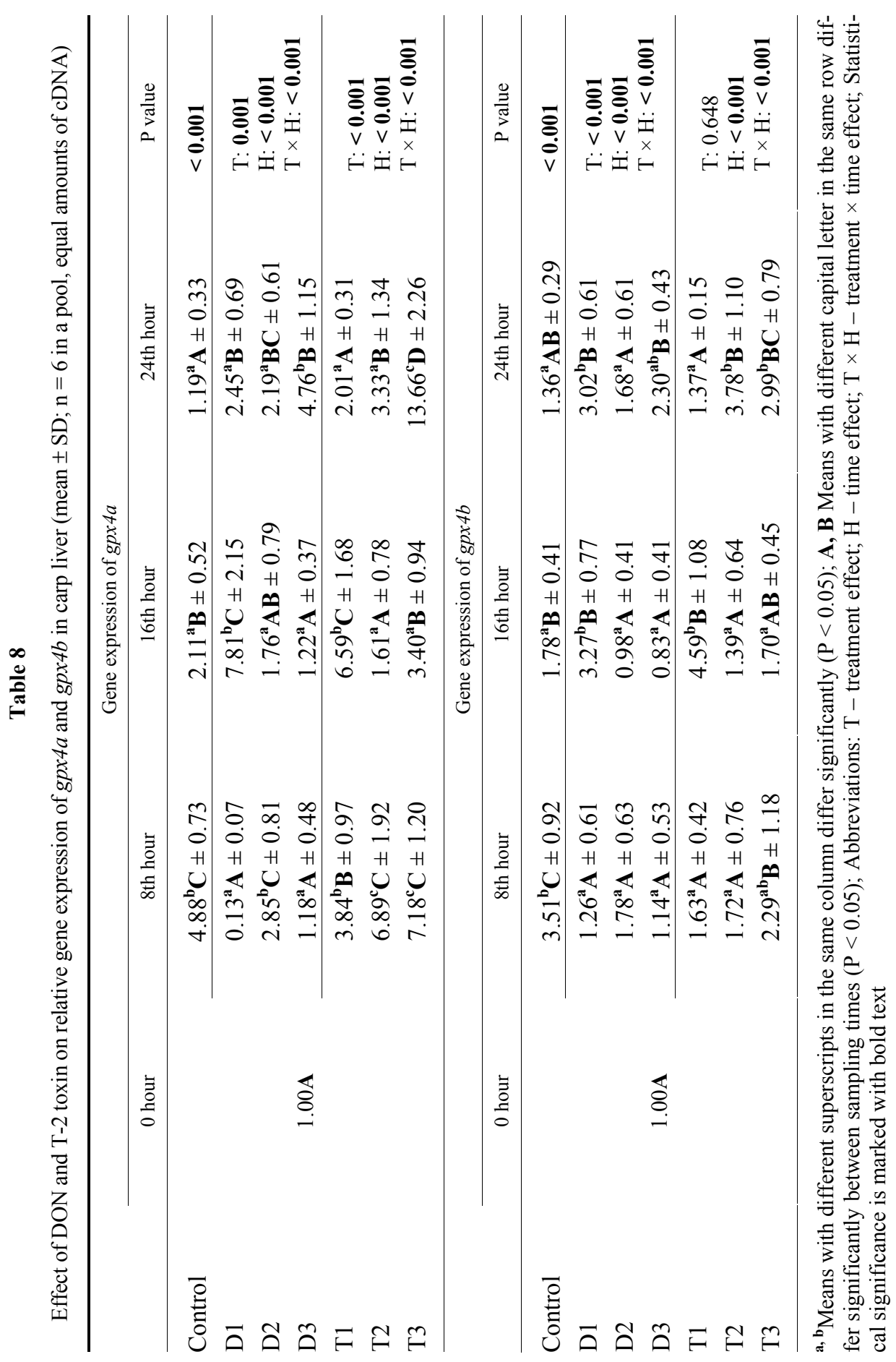


SHORT-TERM EFFECTS OF T-2 TOXIN OR DEOXYNIVALENOL IN COMMON CARP
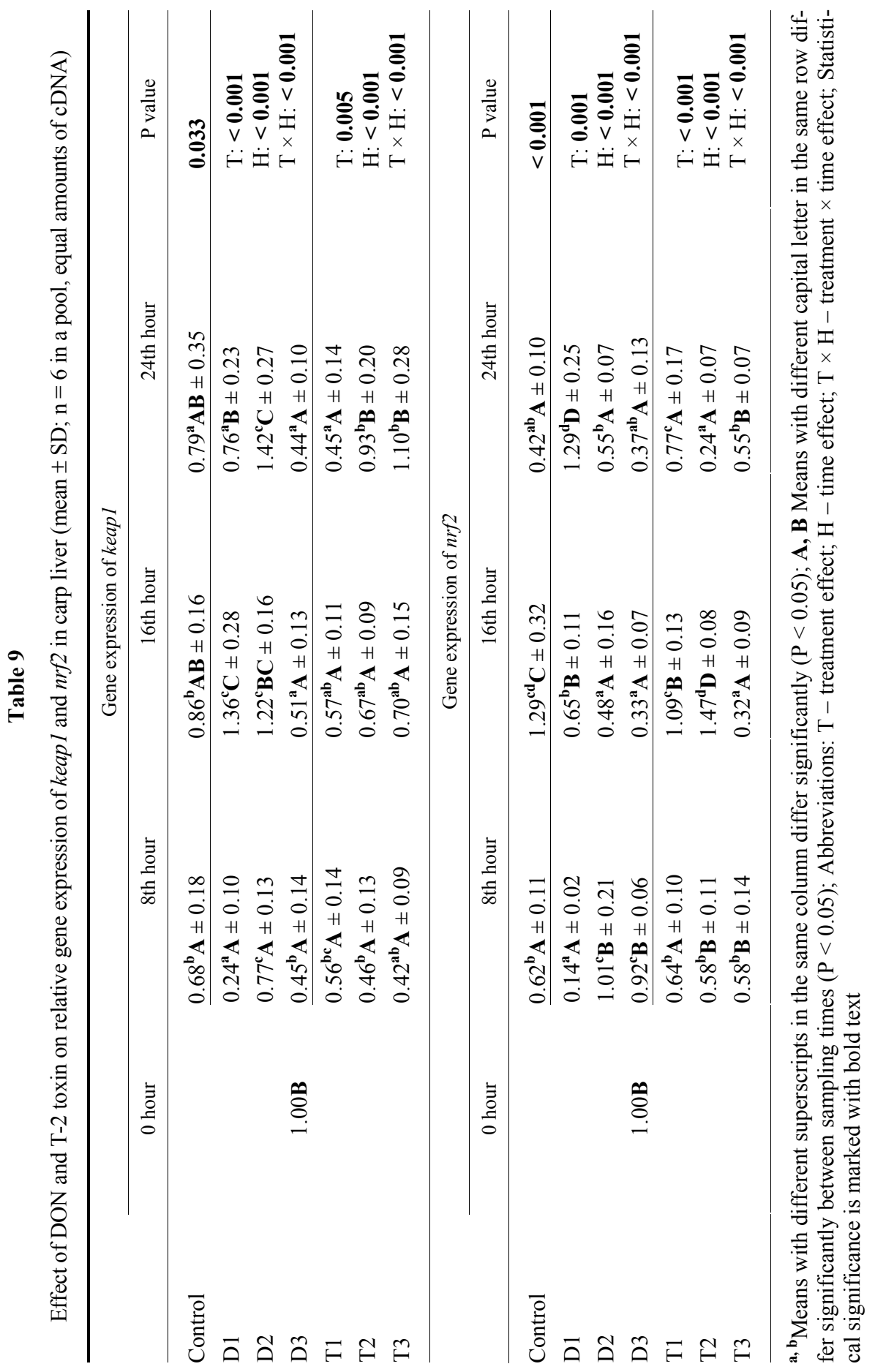
GR activity was significantly lower in the T3 group at the 8 th $\mathrm{h}$ but higher at the 16th $\mathrm{h}$ as compared to the control, and it was higher in the T2 group at the 24th h (Table 7).

The expression of gpx4a and gpx $4 b$ genes showed a dual response during the experimental period. At 8th $\mathrm{h}$ a downregulation was observed in all mycotoxin-treated groups, which was significant as compared to the control in the D1 and D3 groups in case of gpx4a, and in all the three DON-treated and the T1 and T2 groups in case of gpx $4 b$. This downregulation was followed by induction, which occurred at the 16th $\mathrm{h}$ in the T1 and D1 groups. However, these values returned to the control level with the exception of the D1 group, in which the elevation was still significant even at the 24 th $h$. In the T2 and D2 groups, an elevating trend was found, which was significant at the 24th $\mathrm{h}$ in the case of T-2 toxin exposure. The highest applied doses of both mycotoxins (Groups T3 and D3) caused continuous induction, which was significant as compared to the control at the 24th $\mathrm{h}$ in the case of $g p x 4 a$, and in case of gpx $4 b$ in the T3 group (Table 8).

The gene expression of keapl decreased at the 8th $\mathrm{h}$ in the D1 group and increased at the 16th $\mathrm{h}$ but returned to the control level thereafter. In the D2 group, it was elevated at the 16th and 24th h, while in the D3 group it was lower at the 16th hour as compared to the control. There was no significant difference from the control in the other treatment groups and at other sampling points (Table 9).

The gene expression of $n r f 2$ was significantly lower in the D1 group at the 8th and 16th $\mathrm{h}$, followed by a significant elevation at the 24th hour, while in Groups D2 and D3 significant elevation was found at the 8th $\mathrm{h}$, followed by a significant downregulation at the 16th $\mathrm{h}$ and an increase back to the control level at the 24th h. T-2 caused a significant elevation in the T1 group at the 24th h, but in the T3 group a significant decrease was observed at the 16th h. However, there was no significant difference from the control at the other sampling points (Table 9).

\section{Discussion}

The approximate transit time of feed, which depends on the actual water temperature in fishes as poikilothermic animals (Farkas et al., 1980), was $16 \mathrm{~h}$ in the control group.

The high rate of mortality (19\% was observed only in the T3 group treated with the highest dose of T-2 toxin) confirms that T-2 toxin has the highest toxicity among trichothecene mycotoxins even in fishes (Anater et al., 2016).

Most of the parameters investigated revealed significant changes not only in the mycotoxin-treated groups but also in the control group as a function of time, which might be explained by a novel theory about circadian rhythms in the generation and scavenging of ROS in a variety of species as reviewed by Wulund 
and Reddy (2015). Another possible cause of these changes, even in the control group, would be the effect of the presence or lack of nutrients in the gastrointestinal tract during the experimental period, because a single oral addition of feed was used.

The level of CD and CT showed marked elevation due to the effect of DON and a similar trend due to the effect of T-2 toxin at the 16th h but not later, which suggests an initiation of ROS formation after the mycotoxins are absorbed and reach the liver. The final phase of the process, as was shown by the changes of TBARS, was affected by the highest dose of DON (Group D3) at the 16th and 24th $\mathrm{h}$. These results suggest that ROS formation occurred in the liver as an early effect of the single oral dose of mycotoxins, but it was controlled later by the antioxidant system. According to the results, TBARS content increased significantly only due to the effect of the highest dose of DON (D3), which implies that ROS formation was lower in the other treatment groups. This was probably linked to the transit time of feed particles, which was almost the same period as that available for the absorption of mycotoxins, because of the short large intestine of carp (Kapoor et al., 1976). On the other hand, the glutathione redox system responded rapidly and firmly, where also the 16th-h sampling point seemed to be a key time period at all applied doses of DON or T-2 toxin. The parameters of lipid peroxidation returned to the control level at the 24th hour, which suggested an effective defence against oxidative stress, and this was maintained within the transit time of feed particles. This result supports our previous findings with feeding lower levels of T-2 (0.52 or $2.45 \mathrm{mg} \mathrm{kg}^{-1}$ feed) in common carp, when elevated levels of GSH and GPx were found after 7 and 28 days of mycotoxin exposure (Balogh et al., 2009). Another long-term trial with T-2 toxin (4.11 mg T-2 and $0.45 \mathrm{mg}$ HT-2 toxin $\mathrm{kg}^{-1}$ feed) and DON (5.96 and $0.33 \mathrm{mg}$ 15 -acetyl DON kg${ }^{-1}$ feed) also supports the findings of the present trial. In that trial, the parameters of lipid peroxidation did not differ, therefore they did not show oxidative stress; however, GPx activity decreased in the group challenged with T-2 toxin. The expression of GPx genes was continuously overregulated by DON exposure in that long-term trial, while T-2 toxin had no such effect (Pelyhe et al., 2016). The differences between gene expression and activity at the same time can be explained by the post-translational modification of GPx, which enhanced activity (Fritz et al., 2012).

The activities of GST or GR also increased in the 24-h period but did not show a clear elevating trend. These results are supported by the previous data of Kravchenko et al. (1989) who found slightly elevated GST activity, but in a longer period ( 3 days) of T-2 toxin exposure.

The gene expression of gpx $4 a$ and gpx $4 b$ showed a dual response during the trial. A downregulation occurred after $8 \mathrm{~h}$ which then changed into upregulation in the case of the lowest dose of DON (D1) or T-2 toxin (T1) at $16 \mathrm{~h}$, and at $24 \mathrm{~h}$ when using higher doses (T2, T3, D2 and D3). Trichothecene mycotoxins, 
such as T-2 toxin or DON, possibly induce ROS formation and cause oxidative stress which mediates the genes involved in the antioxidant system, through the redox-sensitive Nrf2/ARE pathway (Suzuki and Yamamoto, 2015). This pathway was possibly blocked by a feedback mechanism after $8 \mathrm{~h}$, which may be caused by the inhibitory effect of trichothecenes on RNA synthesis (Holladay et al., 1995). However, this downregulation was followed by an upregulation depending on time and dose, which can be linked to the classic regulatory pathway of the Keap1-Nrf2-ARE mechanism induced by oxidative stress (Taguchi et al., 2011).

The findings of the present study support our hypothesis about the importance of the presence of mycotoxin in the gastrointestinal tract, which was linked to the measured approximate transit time. In $16 \mathrm{~h}$ all the applied doses of DON or T-2 toxin had an effect on the parameters of lipid peroxidation and the antioxidant system. The results suggested that the lower doses could be absorbed and metabolised rapidly, thus their effect lasted only within the period of the present experiment, while the higher doses had delayed effects on gene expression, which may be related to the effect of the higher absorbed amounts of mycotoxins and/or the delayed over-reaction of the Nrf2-ARE pathway.

The results also suggested that DON and T-2 toxin have different mechanisms of action on the chosen endpoints. On the one hand, they initiate ROS formation and lipid peroxidation, and consequently activate the enzymatic antioxidant system; on the other hand, they influence the expression of the gpx4a and gpx $4 b$ genes which encode one of the most important antioxidant enzymes in fish, phospholipid hydroperoxide glutathione peroxidase, GPx4 (Wang et al., 2012). In addition, nrf 2 and keapl genes, which encode the regulators of antioxidant response elements, also revealed changes as an effect of the mycotoxin exposure. The gene expression of Keap1, which plays a role in the ubiquinilation and degradation of $\mathrm{Nrf2}$, the master regulator of numerous antioxidant genes, decreased in a dose- and time-dependent manner, while $n r f 2$ gene expression showed opposite changes and resulted in activation of the antioxidant gene cluster.

In conclusion, it can be stated that the parameters of oxidative stress changed according to the dose and duration of mycotoxin exposure, in particular due to the effect of DON and 15-acetyl DON but to a less extent due to T-2 and HT-2 toxin. GSH content and GPx activity showed higher levels than in the control at the 16th $\mathrm{h}$, when mycotoxin absorption was possibly finished, according to the approximate transit time. These changes are coincide with the gene expression profile of GPx, and also with the changes of its regulator, namely the Nrf2ARE pathway. This means that, according to the hierarchical model of oxidative stress, high doses of trichothecene mycotoxins, namely T-2 or DON, induce mild oxidative stress in the liver of common carp. 


\section{Acknowledgements}

This study was supported by the János Bolyai Research Scholarship (BO/261/13 to $\mathrm{KB}$ and $\mathrm{BO} / 499 / 13$ to JSz-F), Hungarian Scientific Research Fund (OTKA PD104823) to KB, New National Excellence Program of the Ministry of Human Capacities to CsP and Research Centre of Excellence 1476-4/2016/FEKUT grants.

\section{References}

Anater, A., Manyes, L., Meca, G., Ferrer, E., Luciano, F. B., Pimpão, C. T. and Font, G. (2016): Mycotoxins and their consequences in aquaculture: A review. Aquaculture 451, 1-10.

AOAC (1984): Official Methods of Analysis of the Association of Official Analytical Chemists (28.054). 14th edition. Arlington, VA, USA.

Balogh, K., Heincinger, M., Fodor, J. and Mézes, M. (2009): Effects of long term feeding of T-2 and HT-2 toxin contaminated diet on the glutathione redox status and lipid peroxidation processes in common carp (Cyprinus carpio L.). Acta Biol. Szegediensis 5, 23-27.

Binder, E. M., Tan, L. M., Chin, L. J., Handl, J. and Richard, J. (2007): Worldwide occurrence of mycotoxins in commodities, feeds and feed ingredients. Anim. Feed Sci. Technol, 137, $265-282$.

Botsoglou, N. A., Fletouris, D. J., Papageorgiou, G. E., Vassilopoulos, V. N., Mantis, A. J. and Trakatellis, A. G. (1994): Rapid, sensitive and specific thiobarbituric acid method for measuring lipid peroxidation in animal tissue, food and feedstuff samples. J. Agric. Food Chem. 42, 1931-1937.

Farkas, T., Csengeri, I., Majoros, F. and Oláh, J. (1980): Metabolism of fatty acids in fish: III. Combined effect of environmental temperature and diet on formation and deposition of fatty acids in the carp, Cyprinus carpio Linnaeus 1758. Aquaculture 20, 29-40.

Fodor, J., Németh, M., Kametler, L., Pósa, R., Kovács, M. and Horn, P. (2006): Novel methods of Fusarium toxins' production for toxicological experiments. Acta Agr. Kaposváriensis 10, 277-285.

Fritz, K. S., Galligan, J. J., Hirschey, M. D., Verdin, E. and Petersen, D. R. (2012): Mitochondrial acetylome analysis in a mouse model of alcohol-induced liver injury utilizing SIRT3 knockout mice. J. Proteome Res. 11, 1633-1643.

Habig, W. H., Pabst, M. J. and Jakoby, W. B. (1974): Glutathione S-transferases: The first enzymatic step in mercapturic c acid formation. J. Biol. Chem. 249, 7130-7139.

Hermesz, E. and Ferencz, A. (2009): Identification of two phospholipid hydroperoxide glutathione peroxidase (gpx4) genes in common carp. Comp. Biochem. Physiol. C 150, 101-106.

Holladay, S. D., Smith, B. J. and Luster, M. I. (1995): B-lymphocyte precursor cells represent sensitive targets of T-2 mycotoxin exposure. Toxicol. Appl. Pharmacol. 131, 309-315.

Hooft, J. M., Elmor, A. E. H. I., Encarnação, P. and Bureau, D. P. (2011): Rainbow trout (Oncorhynchus mykiss) is extremely sensitive to the feed-borne Fusarium mycotoxin deoxynivalenol (DON). Aquaculture 311, 224-232.

Jiang, J., Shi, D., Zhou, X. Q., Yin, L., Feng, L., Liu, Y., Jiang, W. D. and Zhao, Y. (2015): Effects of glutamate on growth, antioxidant capacity, and antioxidant-related signaling molecule expression in primary cultures of fish enterocytes. Fish Physiol. Biochem. 41, 1143-1153.

Kapoor, B. B., Smit, H. and Verighina, I. A. (1976): The alimentary canal and digestion in teleosts. Adv. Marine Biol. 13, 109-239.

Kendziorski, C. M., Zhang, Y., Lan, H. and Attie, A. D. (2003): The efficiency of pooling mRNA in microarray experiments. Biostatistics 4, 465-477. 
Kravchenko, L. V., Galash, V. T., Avreneva, L. T. and Kranauskas, A. E. (1989): On the sensitivity of carp, Cyprinus carpio, to mycotoxin T-2. J. Ichthyol. 29, 156-160.

Lawrence, R. A. and Burk, R. F. (1976): Glutathione peroxidase activity in selenium deficient rat liver. Biochem. Biophys. Res. Commun. 71, 952-956.

Livak, K. J. and Schmittgen, T. D. (2001): Analysis of relative gene expression data using realtime quantitative PCR and the 2(-DeltaDelta C(T)) method. Methods 25, 402-408.

Lowry, O. H., Rosenbrough, N. J., Farr, A. L. and Randall, R. J. (1951): Protein measurement with the Folin phenol reagent. J. Biol. Chem. 193, 265-275.

Nel, A., Xia, T., Mädler, L. and Li, N. (2006): Toxic potential of materials at the nanolevel. Science 311, 622-627.

Pelyhe, Cs., Kövesi, B., Zándoki, E., Kovács, B., Szabó-Fodor, J., Mézes, M. and Balogh, K. (2016): Effect of 4-week feeding of deoxynivalenol or T-2-toxin-contaminated diet on lipid peroxidation and glutathione redox system in the hepatopancreas of common carp (Cyprinus carpio L.). Mycotox. Res. 32, 77-83.

Pietsch, C., Schulz, C., Pere Rovira, P., Kloas, W. and Burkhardt-Holm, P. (2014): Organ damage and hepatic lipid accumulation in carp (Cyprinus carpio L.) after feed-borne exposure to the mycotoxin, deoxynivalenol (DON). Toxins 6, 756-778.

Pietsch, C., Katzenback, B. A., Garcia-Garcia, E., Schulz, C., Belosevic, M. and Burkhardt-Holm, P. (2015): Acute and subchronic effects on immune responses of carp (Cyprinus carpio L.) after exposure to deoxynivalenol (DON) in feed. Mycotox. Res. 31, 151-164.

Poston, H. A., Coffin, J. L. and Combs, G. F. Jr. (1982): Biological effects of dietary T-2 toxins on rainbow trout, Salmo gairdneri. Aquat. Toxicol. 2, 79-88.

Pussemier, L., Piérard, J. Y., Anselme, M., Tangni, E. K., Motte, J. C. and Larondelle, Y. (2006): Development and application of analytical methods for the determination of mycotoxins in organic and conventional wheat. Food Addit. Contam. 23, 1208-1218.

Rahman, I., Kode, A. and Biswas, S. K. (2007): Assay for quantitative determination of glutathione and glutathione disulphide levels using enzymatic recycling method. Nat. Prot. 1, 31593165 .

Šišperová, E., Modrá, H., Ziková, A., Kloas, W., Blahová, J., Matejová, I., Živná, D. and Svobodová, Z. (2015): The effect of mycotoxin deoxynivalenol (DON) on the oxidative stress markers in rainbow trout (Oncorhynchus mykiss, Walbaum 1792). J. Appl. Ichthyol. 31, 855-861.

Smith, I. K., Vierhelle, T. L. and Thorne, C. A. (1988): Assay of glutathione reductase in crude tissue homogenates using 5,5'-dithiobis(2-nitrobenzoic acid). Anal. Biochem, 175, 408-413.

Suzuki, T. and Yamamoto, M. (2015): Molecular basis of the Keap1-Nrf2 system. Free Radic. Biol. Med. 88, 93-100.

Taguchi, K., Motohashi, H. and Yamamoto, M. (2011): Molecular mechanisms of the Keap1-Nrf2 pathway in stress response and cancer evolution. Genes Cells 16, 123-140.

Trebstein, A., Seefelder, W., Lauber, U. and Humpf, H. U. (2008): Determination of T-2 and HT-2 toxins in cereals including oats after immunoaffinity cleanup by liquid chromatography and fluorescence detection. J. Agric. Food Chem. 56, 4968-4975.

Wang, L., Harris, S. M., Espinoza, H. M., McClain, V. and Gallagher, E. P. (2012): Characterization of phospholipid hydroperoxide glutathione metabolizing peroxidase (gpx4) isoforms in Coho salmon olfactory and liver tissues and their modulation by cadmium. Aquatic Toxicol. 114-115, 134-141.

Wulund, L. and Reddy, A. B. (2015): A brief history of circadian time: The emergence of redox oscillations as a novel component of biological rhythms. Perspect. Sci. 6, $27-37$. 